\title{
EDITORIAL
}

\section{LEARNING CITIES - AN INFLUENTIAL TOPIC FOR ADULT EDUCATION AND LEARNING, DRAWING ATTENTION TO INCLUSION, COLLABORATION AND INNOVATION}

This thematic issue of Studies in Adult Education and Learning puts the topic of learning cities into the focus of analysis since the topic itself has been able to connect several matters of adult learning in the contexts of both participation and performance, the latter having strong references to professionalisation, over the last fifty years.

It is no surprise that the topic has recently been attached to issues concerning the quality of education as part of the discourse on Sustainable Development Goals and simultaneously reflects the question of using collaboration to create better communities by developing education and other welfare services in urban areas. However, certain facets of learning cities have generated tensions because of their political, economic, and societal aspects, and in terms of global, national, and local/regional views on the roles, aims, and choices of learning cities. Discourses at the recent PASCAL International Observatory or the UNESCO Institute for Lifelong Learning (UIL) conferences have signalled the limitations of power, structures, and policies and recommended shifting from the current models of learning cities towards community focuses on inclusion, equity, and equal opportunities (PASCAL Observatory, 2019; UIL, 2019a).

When one makes a thorough survey of the evolution of learning cities, it becomes obvious that their beginnings are connected to the Organisation for Economic Co-operation and Development (OECD) and its goal to promote regional economic development based on effective knowledge transfer as part of a new and more modern knowledge-based society (see Németh's article).

However, these beginnings also provided valuable new insights to several international organisations like the United Nations Educational, Scientific and Cultural Organization (UNESCO) and the newly established European Union (EU), who decided to make use of the concept in the shape of learning city-region formations. Inclusive measures were in place to raise participation in learning on the one hand, and to develop the quality and effectiveness of formal, non-formal, and informal education on the other. The importance 
of a well-promoted learning society framework was highlighted at the turn of the millennium with the Millennium Development Goals (MDGs), UNESCO's vision of Education for All and with EU's programme to develop regions of lifelong learning (R3L) as part of the Lisbon programme (European Communities, 2002).

At the same time, the Korean initiative of Learning Cities, part of a broader national campaign to promote a policy of lifelong education, attached itself to participation-led community actions in order to achieve a better atmosphere of learning (demonstrated in Park's paper).

In this respect, this thematic issue tries to examine the trends and issues concerning some particularly challenging elements in the evolution of learning cities in order to address the constraints of mainly societal aspects when attempting to clarify influential factors of change and development. Each of the collected papers is analytical in its scope and, simultaneously, has tried to point out some elements of learning within communities and local/regional limitations which may either form or dismantle the model under scrutiny. The five papers have highlighted some particularly relevant aspects of learning city development with five individual approaches:

- the Korean example discusses the place of learning cities in the context and perspective of a learning society orientation based on a comprehensive literature review (Park's paper);

- the Serbian example demonstrates the changing nature and impact of learning sites in learning cities by analysing and relating the topic itself to public pedagogical and civic education concerns (Popović, Maksimović, Jovanović and Joksimović's paper);

- the Irish example discusses the matter of community building in the focus of capacity building, sustainability, and resilience, and also reflects on the special impact of raising capital, from human to cultural (Ó Tuama's paper);

- the comparative focus on the learning city models of Cork and Pécs relates some composite factors of the learning city evolution and each other's similarities and differences (Németh's paper);

- the practical example of the Learning City of Espoo, as is evident from the title of the paper, emphasizes concerns for sustainability and community focus (Erkkilä's paper).

Another very important element of this collection is underlining the necessity of community focus and community development as something like a 'quasi factor' of legitimation in all five examples. Learning cities could have developed a number of alternative orientations in the last two decades, however, it became inevitable to integrate the technology-driven innovations of smart, creative cities and the stakeholder-driven policy-guided formations of educating cities. More precisely, UNESCO's involvement has made it possible to recognise the roles and responsibilities of city leadership, but to firmly establish collaborations and inclusion as the keys to success for lifelong learning and for learning communities (UIL, 2016). 
Each of the examples in the thematic section of this issue embodies its own set of values so that it reflects the human focus of learning cities and clearly demonstrates the challenge of engaging both citizens and their communities in campaigning for living and learning in the diverse environments that a city and its region encompass. Learning cities very openly reflect the fact that cities can only develop when they build upon the capacities of their communities and seek a reliable consensus on how to move forward in difficult times. The United Nation's (UN) Agenda 2030 for Sustainable Development has indicated that urban environments will encounter a number of difficulties which will need to be tackled by setting global goals and taking local and regional action (United Nations, 2015).

The examples of learning cities will also help us understand the necessity of recognising the public benefits of community-based learning in learning cities and integrating both individual and community aspirations in urban settings of knowledge transfer and skills development. In this regard, some significant organisations and institutions of education and culture will definitely play a significant role, such as universities (eucen, 2018) and museums, libraries and community learning centres (Németh, 2018).

The first paper on Korean Learning Cities teaches us that the relationship between a learning city and a learning society has always entailed strong concerns about quality. For this reason, the aim of this learning city model is to emphasize the creation of a just society, both a great challenge and an opportunity in Korean society, as participatory action has a strong focus on equal opportunities. Park's paper demonstrates that increasing participation and realising equal opportunities require commitment and engagement, but also the involvement of citizens as learners and agents of learning to strengthen community development within learning cities and beyond. Not only learning itself but social inclusion through learning may help engage citizens in community affairs and community development to tackle inequalities through bottom-up formations and projects to empower citizens with civic values, attitudes, and by learning the skills of participation through their own practice.

The Serbian example can be regarded as a critical interrogation demonstrating that although the concept of learning cities-regions as developed by the OECD had a primarily economic angle, it is UNESCO and its global network of learning cities which introduced the importance of the community, the social perspective of learning cities, and highlighted the importance of participatory concerns and inclusive learning environments. Belgrade's approach, however, introduces a challenging focus on civic actions, reconceptualising the public sphere, and the active creation of space in the city. Popović, Maksimović, Jovanović, and Joksimović offer a broadening of the concept of the learning city to include cities with strong civic movements and actions, strengthening non-formal learning to result in critical thinking and active citizenship. Public pedagogy and civic education may be of help in this regard and get citizens to "co-create urban spaces". In this framework a city may be recognised both as a context and as an educator, making it possible for public places to become places of learning. 
The third case from Cork, Ireland offers a special critical focus on learning cities. Ó Tuama elaborates upon lifelong learning, community building, and sustainability in Cork Learning City, especially on the Learning Neighbourhoods component to highlight that learning cities have a joint responsibility in building learning communities and, moreover, to prepare and empower them to become resilient and self-organised in order to face the challenges of sustainability and other global changes. Although the concept of Learning Neighbourhoods is essentially about collaboration and coalition building, it is a community building concept articulated through learning. Therefore, it is worth examining and getting an idea of how it may help the citizens of Cork prepare for the challenges posed by issues such as climate, poverty, and inclusion.

In the fourth paper the learning city of Pécs, Hungary, is compared to the complex model of Cork Learning City. Both former European Capitals of Culture (ECoC), Pécs and Cork went on to become learning cities and joined UNESCO's global network, which enables learning cities to collect and share ideas and experiences of community development through learning (UIL, 2017). The paper provides a summary of the main stages in the evolution of learning cities up to their current phase, where the global environment is combined with local and regional characteristics. Besides exploring the similarities and differences that exist between the Cork and the Pécs models, the reader will also find some explanations of the choices for and barriers to further development in the global climate, and the constraints of local and regional realities.

Erkkilä's practical example of the City of Espoo in Finland helps the reader recognise the impact a tradition of learning city-region development can have in strengthening its focus on combining learning and community development with that of innovative technological development for the benefit of its communities. Espoo was already a pioneering city in the 1990s and it worked systematically to join UNESCO's call for learning cities to lead, among other respected cities, toward sustainable development with a vision of dynamism based on collaborative action for sustainable formats and on empowering learners to actively participate and contribute to shaping the flexible learning spaces analysed in this paper. It is not surprising that Espoo combines the expansion of learning opportunities with the joy of learning and that of powerful collaboration.

We hope that this collection can successfully bring together the topic of learning cities and that of adult education and lifelong learning. In association with UNESCO UIL, the examined learning city models help promote better participation, performance, and provision in lifelong learning for all. UNESCO's $4^{\text {th }}$ Global Report on Adult Learning and Education (UIL, 2019b) points out several reasons why we still have a lot to do to turn learning cities into fully developed learning communities, cities, and regions that are inclusive and equitable grounds of human interaction, which promote better understanding and seek out appropriate responses to global and local challenges.

Besides the five thematic papers, this issue also includes two open papers, three reports, and a book review. In "Expansive Learning and Research Practices at the Slovenian Third 
Age University” Matej Urbančič, Meta Kutin, Dušana Findeisen, Maja Mezgec, Nives Ličen and Klara Kožar Rosulnik discuss selected research practices at the Slovenian Third Age University (U3A) and interpret them using the theory of expansive learning. Selected examples of exploratory learning are used to identify the factors that influence the development of exploratory learning. The authors argue that expansive learning at the Slovenian U3A leads to innovative and socially engaged practices. In the second paper, "Sensitivity of Evaluation Practices to Types, Cycles and Fields of Study Programmes," Jernej Širok discusses the concept of quality in higher education. His analysis of judgements on quality in the final expert reports from programme re-accreditation procedures shows that the criticism and frequency of qualitative emphases poorly track the necessities of intrinsic properties of types, cycles and disciplinary foundations of study programmes. This issue is brought to a close with three reports on different anniversaries in the field of adult education. Lidija Črnko reports on the centenary of adult education in Britain and the publication of the Ministry of Reconstruction's landmark report in 1919, Monika Govekar-Okoliš has prepared a report on 100 years of Volkshochschulen in Germany, and Petra Javrh has written about the $60^{\text {th }}$ anniversary of the Association of People's Universities of Slovenia. Our final contribution is "Affective Societies", a book review by Nives Ličen.

Balázs Németh

\section{REFERENCES}

European Communities. (2002). European Networks to promote the local and regional dimensions of Lifelong Learning. The R3L initiative. Call for Proposal. Brussels: European Communities.

eucen. (2018). Position on University Lifelong Learning promoting the Agenda 2030 on Sustainable Development. Retrieved December 15, 2019, from https://eucenstudies.files.wordpress. com/2018/06/36_eucenppaper_ull1-agenda2030sdsedited.pdf

Németh, B. (Ed.). (2018). Learning Cities and Culture Working Together. Pécs: UP.

PASCAL Observatory. (2019). Retrieved December 15, 2019, from http://pascalobservatory.org/

UNESCO Institute for Lifelong Learning. (2016). UNESCO Global Network of Learning Cities. Guiding Documents. Hamburg: UNESCO Institute for Lifelong Learning.

UNESCO Institute for Lifelong Learning. (2017). Learning City Pécs. Hamburg: UNESCO Institute for Lifelong Learning.

UNESCO Institute for Lifelong Learning. (2019a). Global Network of Learning Cities. Retrieved December 15, 2019, from http://uil.unesco.org/lifelong-learning/learning-cities

UNESCO Institute for Lifelong Learning. (2019b). 4th Global Report on Adult Learning and Education. Hamburg: UNESCO Institute for Lifelong Learning.

United Nations. (2015). Transforming our World: Agenda 2030 for Sustainable Development: Resolution adopted by the General Assembly on 25 September 2015. Retrieved December 15, 2019, from https:// www.un.org/ga/search/view_doc.asp?symbol=A/RES/70/1\&Lang=E 